\title{
Preparation of Self Hardening-modelling Polyurethane for Wood Repairing and Cracks Injection
}

\author{
G. A. Meligi, H. H. Elnahas* and A. H. Ammar** \\ Chemistry Dept., Faculty of Science, Ain Shams University, \\ *Radiation Research of Polymer Dept., National Centre for \\ Radiation Research and Technology (NCRRT), P. O. Box 29, \\ Nasr City, Egypt and ${ }^{* *}$ Environmental Dept., Egyptian Airports \\ Company.
}

\begin{abstract}
elf hardening composite as a modelling clay was prepared $\checkmark$ from polyurethane, two parts (A) and (B) where (A) contains polyol (polyether), vinyl acetate versatic ester copolymer (VAcVe) and magnesium silicate or wood powder and (B) contains toluene diisocyanate (TDI) as a hardening agent. The two parts mixed thoroughly giving soft putty like feel, open working time 1-2 $\mathrm{h}$ and cures hard overnight ( $24 \mathrm{~h}$ full cure). Factors affecting working time and full cure were evaluated. Also, measurements of surface hardness, compressive strength, scanning electron microscopy (SEM), water absorption and effect of ionizing radiation were studied.

The suggestion for using the prepared polyurethane composite as clay dries as hard as a rock in the field of wood repair and cracks injection for building walls were recommended.

Keywords: Polyurethane, modelling clay, radiation, wood repair and cracks injection.
\end{abstract}

By increasing the demands for high performance with good property polymeric putties for cracks and joint injection in the surface coating processes for walls and wood, the attempts for producing the putties in the form of modelling clay dries as hard as a rock with good qualities were increased so recently by arrival of clay technology and reaching to some clay putties and coating with good physical and mechanical properties were prepared (Barick and Tripathy, 2010, Herrera et al., 2009 and Sikdar et al.,2008).Polymer/clay composites are one of these improved putties. Clay particles have superior effect on the mechanical, physical, thermal and gas barrier properties of putties and coating (Sikdar and Katti, 2008 and Sikdar et al., 2007). There have been some researches on the 
effects of originally modified clay and nanoclay particles on the physical and mechanical properties of epoxy / clay composite (Kent and Riegel, 2003). The results showed that mechanical and physical properties of composite putties and coatings are extremely better than pure polymer. Polyurethane putties are putties that are based on TDI, so they can be used in outdoor environments because their aromatic structure can cause good resistance to weathering and yellowing (Oliver and Pharr, 1992 and Shyang, 2008) and on the other hand for outdoor used putties as modelling clay and then turns into solid is very important and vital.

In this study self hardening composite as modelling clay was prepared from polyurethane and magnesium silicate or wood powder where, the effect of different amounts of clay; magnesium silicate and also cellulosic powder were investigated by measuring the modelling behaviour and comparing them with pure polyurethane putties.

\section{Experimental}

\section{Material}

Polyether polyol and TDI from Bayer Company were used; originally wood powder from saw dust (palm tree) and magnesium silicate were purchased from Grandy for Chemical Industries, Egypt. VAcVe was purchased from Tibah chemicals, Egypt.

\section{Sample preparation}

Different amount of either wood powder or magnesium silicate were added to the polyol/ VAcVe component and then they were sonicated for $20 \mathrm{~min}$ by sonicator in ambient temperature. After adding the hardener component, isocyanate, in stochometry amount to the polyol/ $\mathrm{VAcVe} /$ wood powder or magnesium silicate blend then they were applied as modelling clay.

TABLE 1. Typical formulation of polyurethane-modelling clay.

\begin{tabular}{|l|c|}
\hline TDI & $16.5 \%$ by wt \\
\hline Polyol (Polyether) & $33.5 \%$ by wt \\
\hline VAcVe & $16.5 \%$ by wt \\
\hline Magnesium silicate or wood powder & $33.5 \%$ by wt \\
\hline
\end{tabular}

\section{Characterization}

\section{Scanning electron microscopy}

SEM was used for investigation the internal fracture morphology of samples bulks and this analysis were carried out with a JSA, 5400 Jeol, Japan.

Egypt. J. Rad. Sci. Applic., Vol. 27, No. 1-2 (2014) 


\section{Hardness test}

Surface hardness was measured according to American Standard for Testing Materials (ASTM D2240) specification, model 306 L type A, D durometer for soft and hard plastic.

\section{Compressive strength}

The machine of compressive strength was Instron 1100 type, England. Compressive strength was calculated as the load required per area to break down the sample $\left(\mathrm{Kg} / \mathrm{cm}^{2}\right)$.

\section{Water absorption}

The clean and dried samples of known wt were immersed in distilled water for $24 \mathrm{~h}$ at $25^{\circ} \mathrm{C}$. The samples were removed, blotted by absorbent paper and quickly weighted. The water absorption percent was calculated as follows:

$$
\text { Water absorption }(\%)=\left(\mathrm{W}_{2}-\mathrm{W}_{1}\right) / \mathrm{W}_{1} \times 100
$$

where, $\mathrm{W}_{1}$ and $\mathrm{W}_{2}$ represent the wt of dry and wet samples, respectively.

\section{Gamma irradiation}

Irradiation was carried out using a cobalt-60 source of $\gamma$-rays manufactured by the Atomic Energy Authority of India, with a dose rate of $0.25 \mathrm{Mrad} / \mathrm{h}$.

\section{Electron beam (EB) irradiation}

Accelerator specifications: Energy: $1.5 \mathrm{MeV}$. Beam current: $25 \mathrm{~mA}$, Power: $37.5 \mathrm{~kW}$. Scan width: variable up to $90 \mathrm{~cm}$.

\section{$U V$-irradiation}

The samples were exposed to the direct sunlight for 6 months in summer season in NCRRT, Atomic Energy Authority, Cairo, Egypt.

\section{Results and Discussion}

\section{Polyurethane modelling-clay processing time}

Fig. 1. shows the working time for modelling process and the time required for full cure for polyurethane as a blank, magnesium silicate and wood powder. Where, the time required for modelling process was determined after $1 \mathrm{~h}$ and initial cure after $2 \mathrm{~h}$ for wood powder and magnesium silicate. Gradually increase the surface hardness till $20 \mathrm{~h}$ recorded for full cure. The presence of 
either wood powder or magnesium silicate enhanced the working time of the modelling clay behaviour of polyurethane.

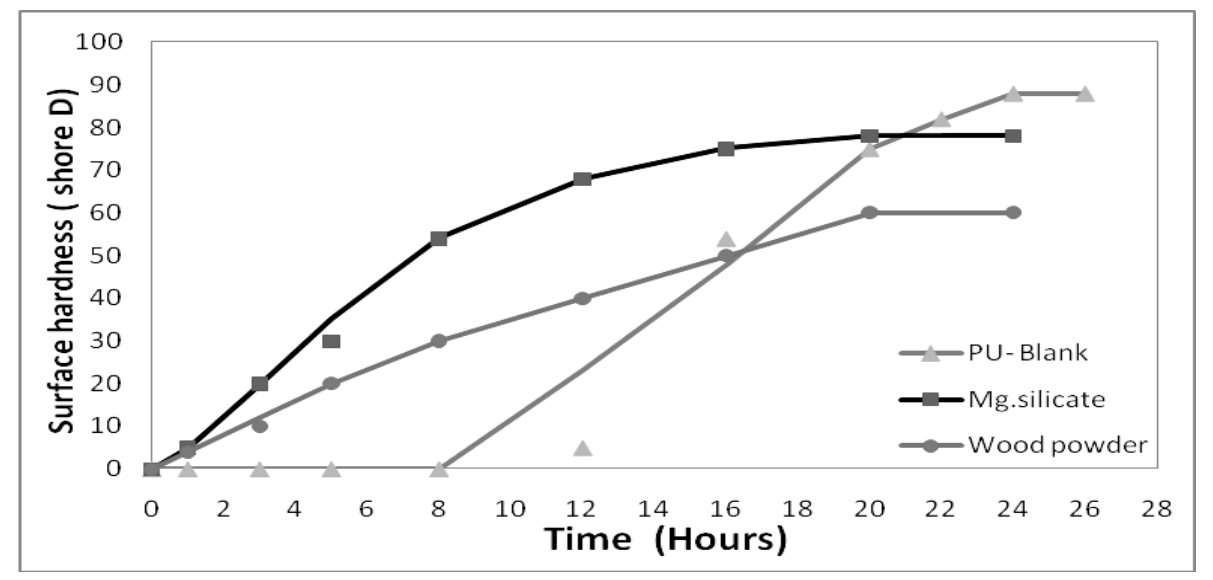

Fig. 1. Effect of time on surface hardness of PU modelling clay (Modelling-curing time).

Fig. 1. also shows the hardness of magnesium silicate at full cure 80 shore $\mathrm{D}$ is higher than wood clay which record 60 shore $\mathrm{D}$, may be due to that the magnesium silicate as inorganic mater penetrate in matrix increasing the hardness, but wood as organic matter react with the PU-matrix as organic compound.

\section{Morphology of polyurethane modelling-clay}

Fig. 2.(a) polyurethane as a blank cured after one day where the initial reaction of polyurethane (started time 1-2 h) leading to a sticky phase that couldn't be able to model.

But as shown In Fig. 2.(b) the addition of VAcVe initiated process that put in order to be absorbed of magnesium silicate clay and wood powder well in the polyurethane matrix.

In Fig. 2.(c) the addition of magnesium silicate shows a well penetrate matrix that could be causing a rock like material at the final state of PUmodelling clay. Also, the addition of wood powder shows a porous matrix which indicate the reaction between the wood and the PU-matrix; formulate the PU-modelling clay as more press able in its processing as shown in Fig. 2.(d).

Egypt. J. Rad. Sci. Applic., Vol. 27, No. 1-2 (2014) 


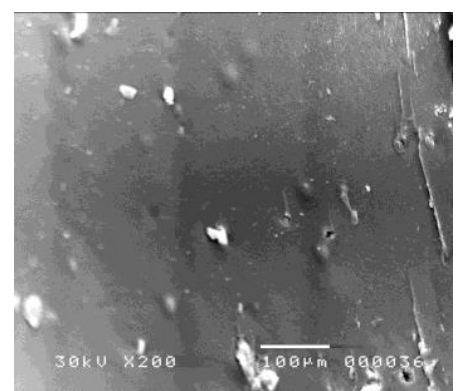

(a)

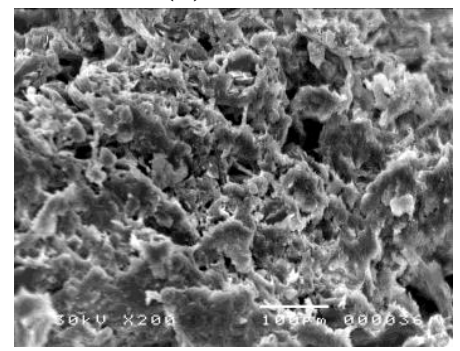

(c)

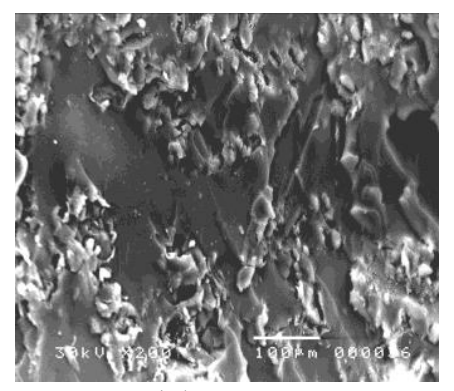

(b)

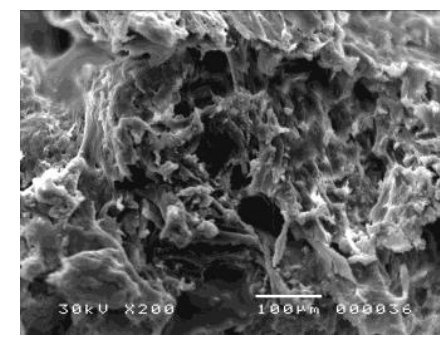

(d)

Fig. 2. SEM of PU-modelling clay.

(a) Polyurethane (Blank), (b) Polyurethane mixed with VAcVe, (c) Polyurethane mixed with VAcVe and Magnesium Silicate and (d) Polyurethane mixed with VAcVe and wood powder.<smiles>Cc1ccc(NC=O)c(NC(=O)OCC(C)C(C)OCC(C)C)c1</smiles>

(A)

$$
\mathrm{A}+\text { Lignin- } \mathrm{OH}
$$

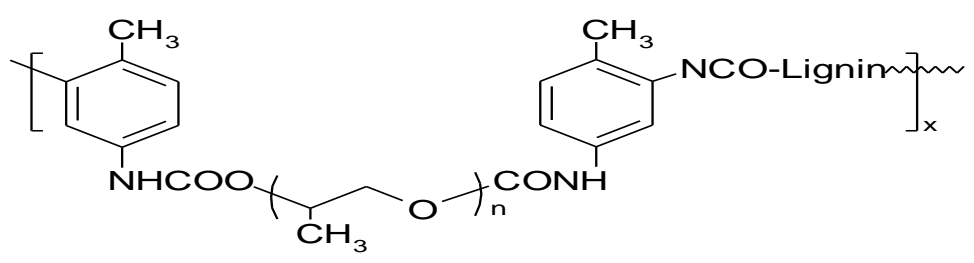

Egypt. J. Rad. Sci. Applic., Vol. 27, No. 1-2 (2014) 


\section{Factors affecting polyurethane modelling-clay properties Effect of TDI}

The surface hardness and compressive strength of the obtained modelling clay after full cure were increased with increasing the ratio of TDI added to the proposed formulation. Fig. 3\&4. illustrate the effect of TDI on surface hardness and compressive strength of PU-modelling clay. It can be seen that the hardness and compressive strength continuously increases as the diisocyanate content increases, starting from $10 \%$ of TDI, till $60 \%$, after that no more increasing.

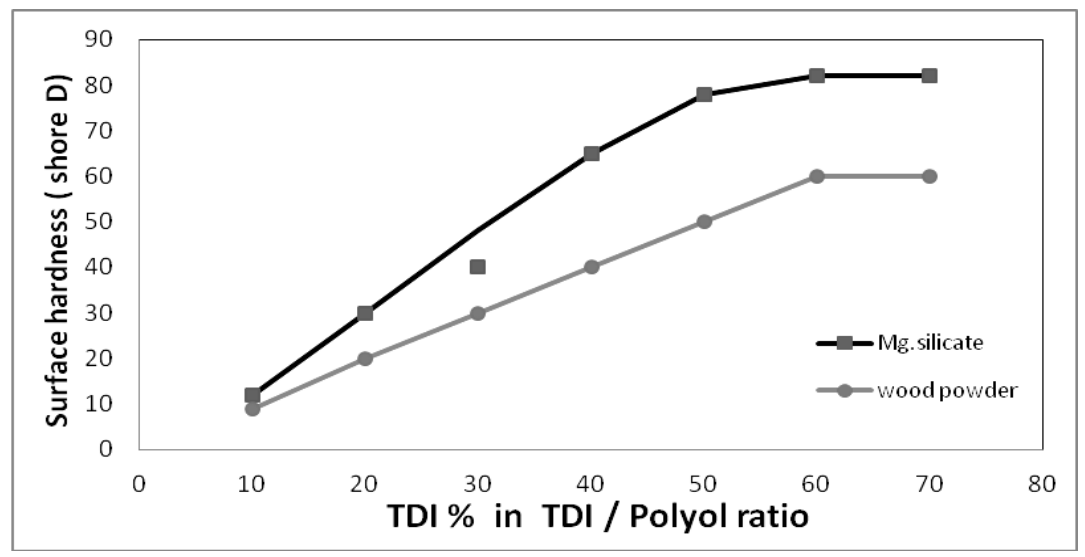

Fig. 3. Effect of TDI percent in TDI / polyol ratio on surface hardness of PUmodelling clay.

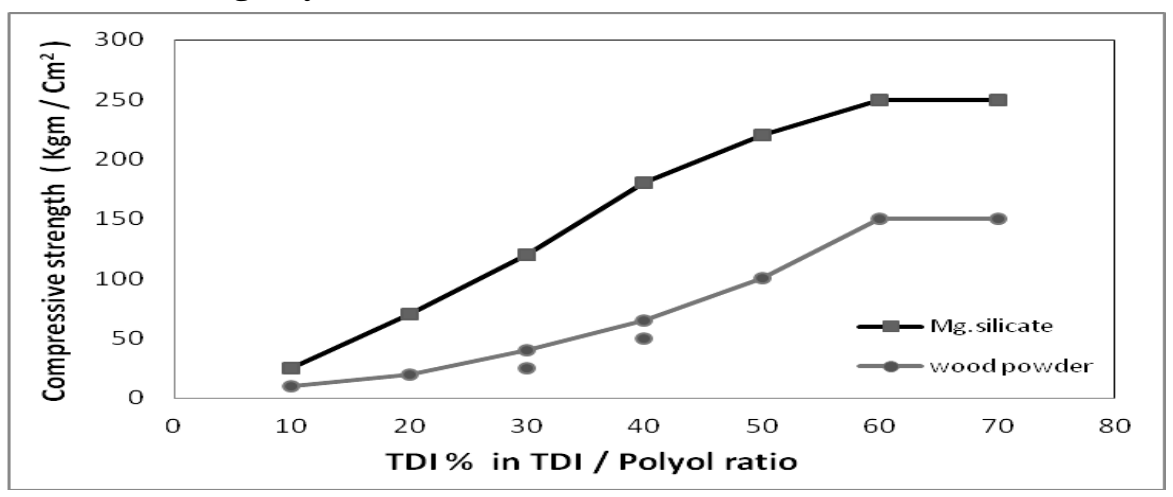

Fig. 4. Effect of TDI percent in TDI / polyol ratio on compressive strength of PUmodelling clay.

The hardness and compressive strength in magnesium silicate is higher than wood powder clay. The reaction illustrate how the physical properties of a Egypt. J. Rad. Sci. Applic., Vol. 27, No. 1-2 (2014) 
urethane polymer changed as the diisocyanate is increased, which include more aromatic ring, as TDI (rigid segment) content; thus emphasizing the importance of reaction stoichiometry in this technology.

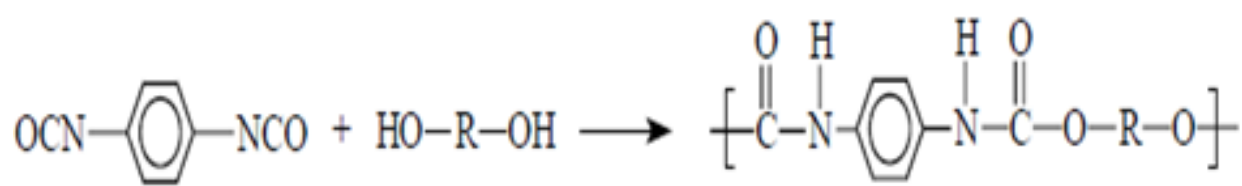

\section{Effect of radiation on hardness and compressive strength}

The effect of different radiation source through the direct exposure on surface hardness and compressive strength of PU-modelling clay were shown in Fig. 5\&6. The surface hardness and compressive strength of PU-modelling clay (full cure) containing magnesium silicate was slightly increased go beyond sun light UV, $\gamma$-ray and EB, indicating the forming of cross linking due to radiation which increase the hardness of the polymer. In case of wood powder modelling clay, radiation with gamma ray decrease the surface hardness and compressive strength more than UV and EB, sign the degradation of polymer which more penetration source of radiation, as well as EB more decrease than UV, referring to the high energy of radiation source compared with UV source. These results are confirming that magnesium silicate is the most suitable filler for outdoor application UV and also for the application located in radiation zones. On the other hand the PU-modelling clay containing wood powder is only recommended for indoor application and apart from UV, EB and $\gamma$-ray.

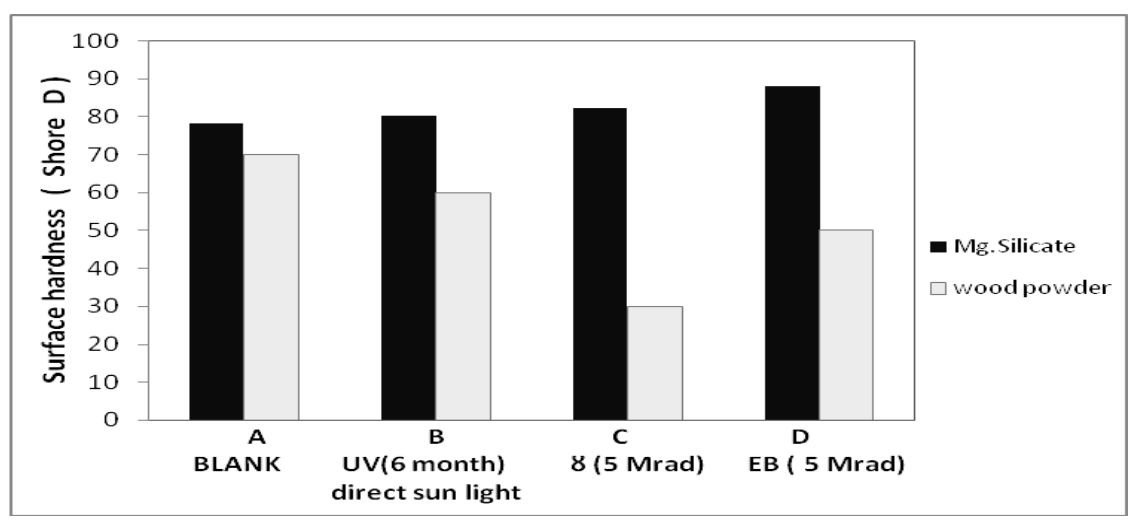

Fig. 5. Effect of different sources of radiation on surface hardness of PU-modelling clay full cure.

Egypt. J. Rad. Sci. Applic., Vol. 27, No. 1-2 (2014) 


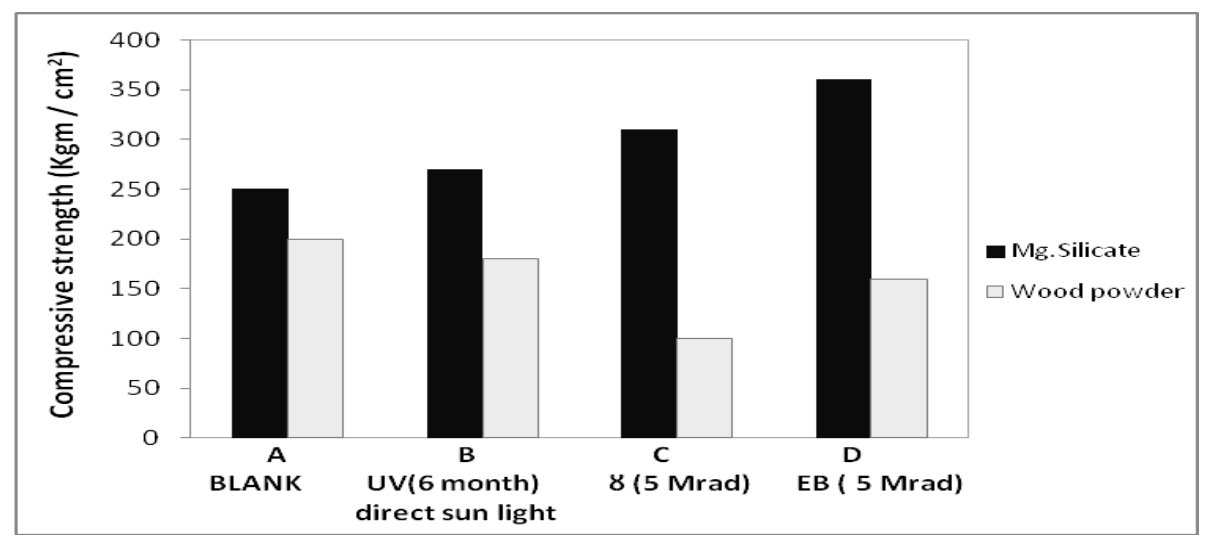

Fig. 6. Effect of different sources of radiation on compressive strength of PUmodelling clay full cure.

\section{Effect of radiation on water absorption of PU-modelling clay}

Polyurethanes are usually classified as polar in nature due to the present of -CONH- and -COOC- groups in the main-chain structure results in a degree of hydrolytic attack in the course of time.
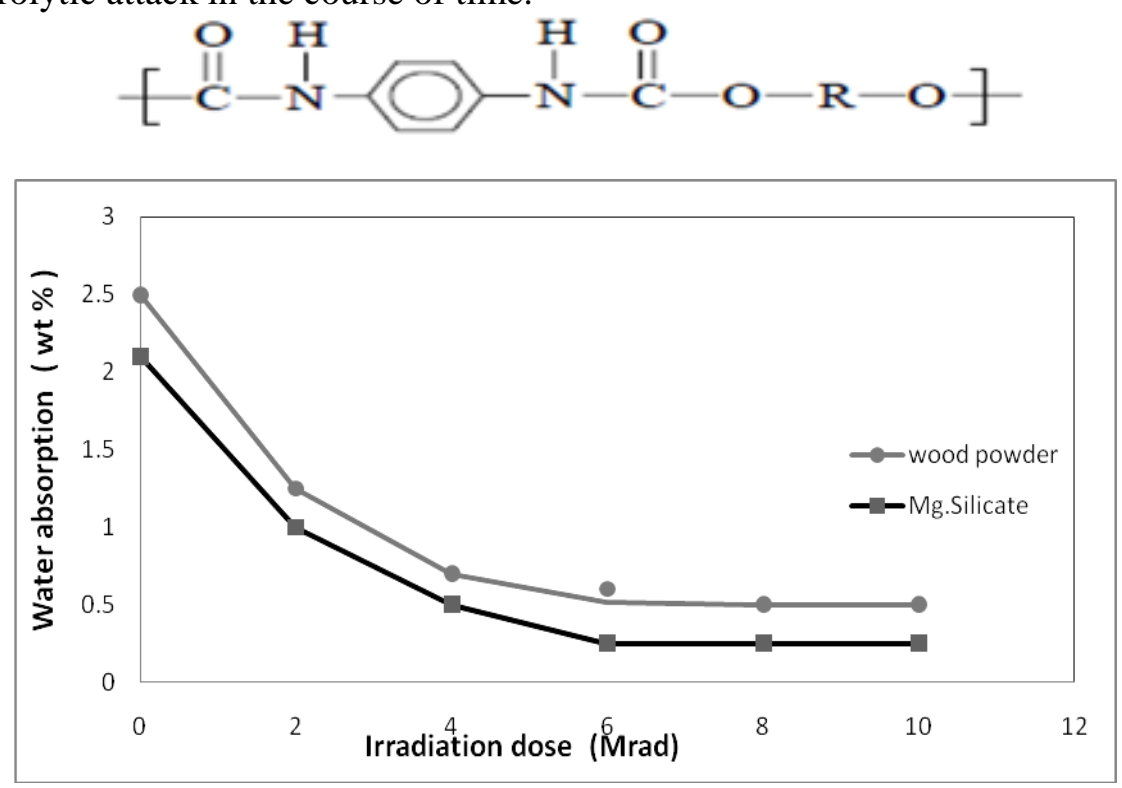

Fig. 7. Effect of irradiation dose of gamma ray on water absorption of PUmodelling clay.

Egypt. J. Rad. Sci. Applic., Vol. 27, No. 1-2 (2014) 
However, possess some hydrophilic character which results in the absorption of moisture from the atmosphere. This phenomenon reduces their basically good consistently high insulation resistance is required.

Fig. 7. show the water absorption was obviously reduced by increasing the irradiation dose. The Fig. also, showed that the irradiation process altered and enhanced the polyurethane to be more resistant to hydrolytic attack. Indicating the cross linking of polymer, in addition, magnesium silicate of clay record more decrease than wood powder.

\section{Conclusion}

In this study we prepared a sculpt, with self-hardening synthesis clay that combines the features and benefits of clay with those of polyurethanes. The results showed that the addition of either wood powder or magnesium silicate are mainly responsible and have superior effects on the properties of modelling clay processing phase and severely depends on the addition of them.

The surface hardness and compressive strength of the obtained modelling clay after full cure were extremely high by increasing the ratio of TDI added to the proposed formulation. It was observed that the presence of either wood powder or magnesium silicate enhanced and increased the working time of the modelling clay behaviour of polyurethane. The results have justified an applied product as PU-modelling clay dries as hard as a rock for use in the field of wood repair and cracks injection.

\section{References}

Sikdar, D., Pradhan, D. R., Katti, K. S. and Mohanty, B. (2008) Altered phase model for polymer-clay nonocomposites. Langmuir, 24, 5599.

Barick, A. K. and Tripathy, D. K. (2010) Effect of organoclay on the morphology, mechanical, thermal and rheological properties of organophilic montmorillonite nanoclay based thermoplastic polyurethane nanocomposites prepared by melt blending. Polm. Eng. Sci., 50, 484.

Herrera Alonso, R., Estevez, L., Lian, H., Kelarakis, A. and Giannelis, E. P. (2009) Nafion-clay nanocomposite membranes: morphology and properties. Polymer, 50, 2402.

Sikdar, D. Katti, K. and Mohanty, B. (2007) Effect of organic modifiers on dynamic and static nanomechanical properties and crystallinity of intercalated clay, polcarbolactam nanocomposites. J. App. Polm. Sci., 105, 790. 
Sikdar, D. and Katti, D. R. (2008) Molecular interactions alter clay and polymer structure in polymer clay nanocomposites. J. Nanotechnology, 8, 1638.

Shyang, C. W. (2008) Tensile and thermal properties of poly (Butylene Terephthalate)/ organo-montmorillonite nanocomposites. Malys. Polym., 3, 1.

Oliver, W. C. and pharr, G. M. (1992) An improved technique for determining hardness and elastic modulus using load and displacement sensing indentation experiments. J. Mat. Res., 7, 1564.

Riegel, E. R. and Kent, J. A. (2003) Handbook of Industrial Chemistry, Chapter 20, p. 740.

(Received: 03/04/2014;

accepted: 12/05/2014)

Egypt. J. Rad. Sci. Applic., Vol. 27, No. 1-2 (2014) 


\title{
تحضير بـولى يوريثان صلصسالى ذاتى التصلب لإستخدامه فى الإي ترميم الاخشاب وحقن الثروخ
}

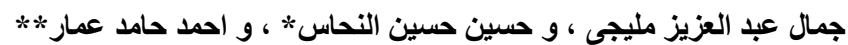

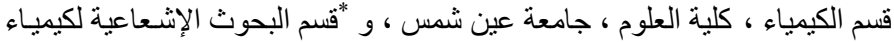

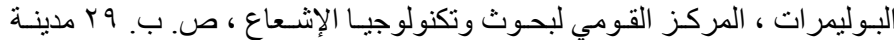

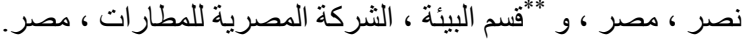

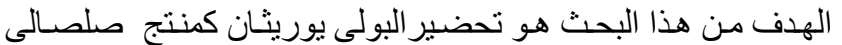

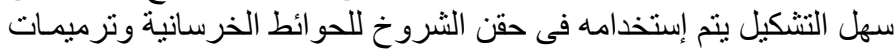

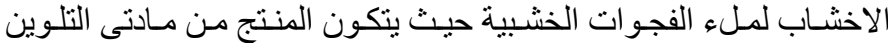

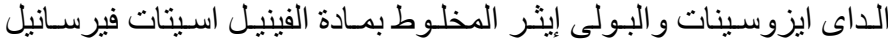

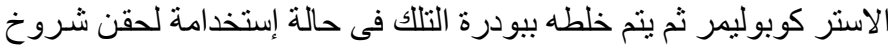

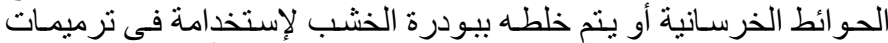

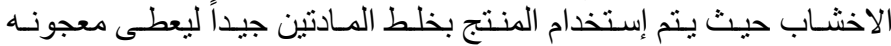

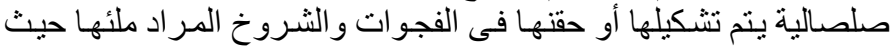

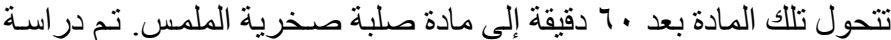

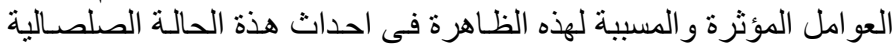

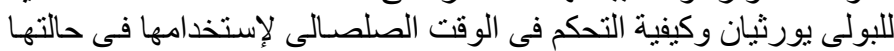

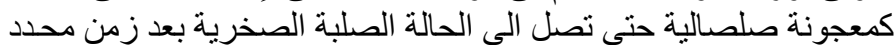

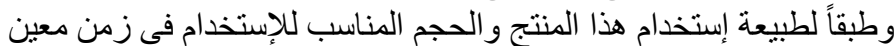

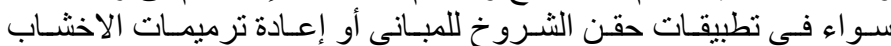

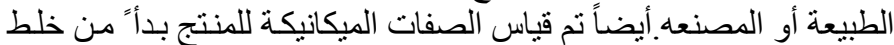

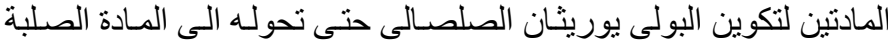

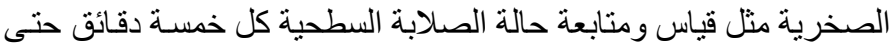

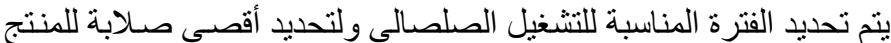

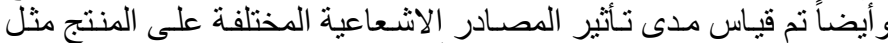

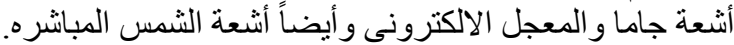

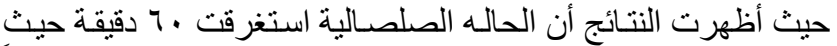

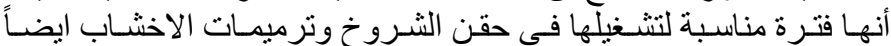

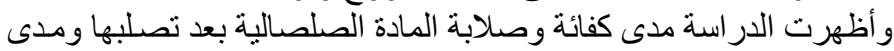

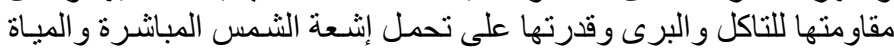

